\title{
The Impact Of Correcting Cognitive Distortions In Reducing Depression And The Sense Of Insecurity Among A Sample Of Female Refugee Adolescents
}

Fatin Mhaidat, The Hashemite University, Jordan

Bassam H. M. ALharbi, The Hashemite University, Jordan

\begin{abstract}
This study aimed at identifying the level of depression and sense of insecurity among a sample of female refugee adolescents, and the impact of an indicative program for reducing cognitive distortions in reducing depression and their sense of insecurity. The study sample consisted of 220 female refugee adolescents, $7^{\text {th }}$ to $1^{\text {st }}$ secondary stage, at the governmental schools in the Zarqa educational directorate, who came to Jordan as a result of war conditions in their home land. The experimental sample contained 20 female refugees, the ones who got the highest scores regarding the depression and sense of insecurity scale, and they were set randomly into 2 groups, experimental and control, with 10 females each. The study used the depression scale, and the sense of insecurity scale. It also used an indicative program consisting of 12 sessions, each one lasts for 45 minutes, with a rate of 2 meetings a week. The results indicated that the female refugee adolescents suffer from a medium-level depression, with an average of (73.97\%), and a sense of insecurity (69.46\%). Findings showed that there was a statistically significant impact at the level $(a=0.05)$ between the control and experimental groups for depression and sense of insecurity among the female refugee adolescents, ascribed to the indicative program.
\end{abstract}

Keywords: Cognitive Distortion; Depression; Insecurity; Adolescents; Refugee

\section{INTRODUCTION}

\section{Asylum}

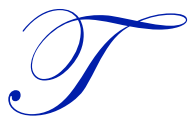

he word "refugee" is considered a definition for every person obliged to leave his original land searching for shelter, having justifiable fear for being exposed to persecution because of racism, religion, nationalism, belonging to a particular group, or because of political opinion, and could not go back due to fear and persecution (Lipson, 1993).

The Arab Convention for Regulating Refugees' Conditions in the Arab countries defined in 1994 the refugee as everyone living outside the country of origin or outside the usual residence, and in case of being with no nationality and having a fear of being persecuted for his race, religion, nationality or belonging to a particular social class, he may seek shelter in the intended country.

The Arab people, over their history, are the most vulnerable ones to crises and mental shocks caused by wars and disasters. In each Arab country, history reveals that the Arab countries are exposed to catastrophes which occurred outside and inside. These catastrophes, which penetrated the human's materialistic and mental environment, torn it up and left it distorted, have influences that extend for long years, leaving behind grief, despair, surrender, and fear of the unknown (Radwan, 2006). 
Millions of people may be forced every year to leave their homes forcibly to join the groups of refugees as a result of wars and foreign domination on the original country, or because of interior political conflicts due to race, religion or nationality (Forstev, 2010).

The number of refugees and displaced has increased from 30 million in 1991 to more than 43millions, who were obliged to leave their countries as a result of conflicts and persecution. This figure is the highest since the mid-1990s. Also, there are millions of displaced people who have left their countries because of natural disasters, in addition to more than 15 million homeless refugees outside their homelands. Moreover, almost 27 million of homeless refugees live inside their homelands because of interior conflicts(UNHCR).

Refugees come from all over the world, after being exposed to brutal experiences, or different types of torture. That is reflected upon them and their families. Most of those who have experienced asylum because of different wars usually experience the post-shock disorders which appeared during the Vietnamese war in the 1970s. Psychological studies revealed the existence of half a million Americans who suffer from this type of disorder after 15 years since the end of the war (Blanch, 1985).

During the first stages of migration, which include leaving the original country, refugees and their families usually suffer from a difficulty in coping with and matching the new culture. Migration is a brave and complex act because it leaves an impact and change in the family's individual and cultural history and identity. Also, starting to accept access into the culture of the host country as well as leaving the original country and its culture form a big mental shock on the family, causing its members to feel defeated and broken, and consequently, feeling insecure (Briskman \& Goddary, 2014).

Kids and adolescents experience asylum as one of the painful, horrible and shocking incidents with which they can't cope within the new community, resulting in experiencing post-shock disorders, such as sleeping disorders like nightmares, walking while sleeping, teeth gnashing and shouting, in addition to school refusal, aggressive behaviors, recidivism to pre-ages and appetite disorders. They also demonstrate emotional disorders like depression, grief, isolation, withdrawal behavior, in addition to the social disorders represented by the inability to communicate with peers, not wanting to go to school, or self-physical disorders like headache and stomachache (Burnett \& Peel, 2001).

According to the formal speech delivered by the High Commissioner for refugees, Antonio Gutterres, in the Security Council on the $18^{\text {th }}$ of April, 2013, the number of Syrian registered refugeeswas nearly (1367413), in Turkey, Lebanon and Jordan. It is expected the number will be 3.5 million by the end of 2013 .

Regarding the number of Syrian refugees in Jordan, it was nearly 1.5 million, according to the official announcements in Jordan.

Also, the number of students enrolled at the public schools in Jordan reached nearly (121882), where (30476) of them were males, and (91403) were females, according to the statistics of the Jordanian Ministry of Education.

As a result of asylum individuals who join the new community are always poorer, and children and adolescents may live with their parents or without them. The family may lose many of its members during wars, and these families may live in refugee camps, which are often not satisfactory for them because of the problems and difficult conditions under which people live inside these camps (Marina, 1998).

\section{Adolescence}

Adolescence is considered one of the important growth stages, particularly that this phase is considered very important for the individual's personal formation, in addition to changes it entails such as the physiological, emotional and social changes. It may result in problems for the adolescent or for the family. Researchers call this stage "the storming phase" (Al-Nibal, 2008). 
Adolescence is characterized by being the stage of preparing for life and taking on responsibility. It is the stage of completing emotional, mental and physical maturity. During this critical phase, the adolescent usually needs reasonable freedom, privileges, trust, his parents' acceptance, in addition to his family's respect and communication. Taking care of adolescents, supporting and guiding them are considered the most important requirements, in addition to the happy home and good model of his parents, of whom he wishes to be proud of (Rice, 1992).

Adolescents usually face several problems and difficulties, such as the psychological troubles as a result of puberty in addition to their seeking taking on responsibility and independence. But they need their parents' support and assistance. Also, they face the social pressures like thinking for themselves, choose and estimate matters, since they want to fulfill their selves, but they have to match their way of thinking and behavior with the prevailing social criteria (Zahran, 1985).

Adolescents suffer from the identity crisis, where they seek the formation of their personal identity, so when it is disturbed; it forms a bad negative outcome for this stage (Al-Rimawi, 2003).

The identity crisis is considered one of the most important crises adolescents face, and it is the conflict they face for identifying and defining themselves, and how they will go in this life (Gewow, 1992).

Kolberg believes that adolescents' having high cognitive capabilities allows them to behave according to high levels of ethical judgment evolution, although many adolescents don't reach this level, but there is a positive relationship between the level of ethical judgment and the social behavior (Al-Rimawi, 2003).

The adolescents' emotions are greatly affected since this stage is considered the period of strong emotions, where they worry for silly reasons, and they express their severe anger through damaging, breaking and threatening to run away. The adolescents' sentiments move towards their selves, and they look deeply on their bodies. Also, they tend to take care of their clothes and their way of speaking in order to be accepted by others. Adolescents usually try to achieve the psychological safety and confidence in the future, and they also live several psychological conflicts. They also seek achieving emotional growth away from parents in order to form their independent personalities. Usually emotional problems reach their peak during this stage (Abu Ulayyan, 2008).

\section{Cognitive Distortions}

Cognitive treatment is one of the modern psychological treatment styles, developed by Beek in the late 1950s. This treatment style became the most successful and the most widely-spread method, designed successfully during the recent decades for helping patients who suffer from depression and panic, professional fear, worry and anger, in addition to addiction and eating disorders.

Cognitive treatment ascertains the examination of ideas and beliefs related to our emotions, behaviors, physical experiences and current events in our life. It also focuses on modifying these ideas through replacing them with other ideas that are more logic, which could help in bringing up adaptive feelings and behaviors (Badesky\&Grundger, 2001).

Beek \& Others (1979) pointed out that the depressor's negative cognitive distortion affects his way of explaining events and his way of dealing with information, so he tends to distort and change information in a way that makes him a victim of his distorted ideas, with no clear evidence that could support these ideas.

Cognitive distortions include: all-or-nothing, over generalization, mental filtering, disqualifying positive events, magnification and minimization, should or must statements, labeling, personalization, and emotional reasoning.

Change in such cognitive distortions among individuals entails a change in feelings and behaviors in a way that they become more positive. 


\section{METHOD}

\section{Participants}

The study sample consisted of all female refugee adolescents of grades $\left(7^{\text {th }}-1^{\text {st }}\right.$ secondary), in 10 public schools in Zarqa, with a total of (220) female students. The experimental sample for the study included 20 students who were chosen randomly from the sample, and distributed randomly into 2 groups, an experimental and control, 10 students each.

\section{The Tools of the Study}

Depression scale:Available scales were used like the list of modified widths for Derogates \& Others (1975). Depression scale consists of 18 items, answered by Yes or No- where Yes is given 2 grades and No is given 1 grade. The highest grade indicates there is depression. The scale's validity and reliability were examined through (Mhaidat, 2011). The logical validity of the scale was examined by being reviewed by 10 referees, Jordanian universities professors, in addition to examining its structuring validity by applying it on a pilot sample consisting of 30 female students outside the study sample. It was revealed that Pearson Correlation Coefficient was (0.937). Reliability was examined by reapplying the scale on a sample of (30) female students after 2 weeks and the reliability coefficient was (0.87).

The scale of Feeling insecure: Despite the use of Maslow's scale which was translated into Arabic by Dawani\&Dirani (1983), the scale consists of 27 items whose answers are done through a binary scale (Yes or No), where (Yes) is given 2 scores and (No) is given 1 score. Mhaidat (2011) examined the validity and reliability of the scale by investigating its logical validity in that it was reviewed by 10 referees, experts from Jordanian universities, in addition to examining its structuring validity where it was nearly (829). The scale's reliability was achieved by reapplying it where Pearson test result was (0.959).

The program of correcting cognitive distortions:The cognitive theory forms the theoretical base for the remedial program, and the program's target is to decrease depression and the sense of insecurity among the female refugee adolescents in public schools. The program consists of 12 sessions, 45 minutes each, with 2 sessions a week.

$1^{\text {st }}$ session: getting to know each other, introducing the program and its objectives, as well as the principles of collective guidance.

$2^{\text {nd }}$ session: understanding the topic of asylum.

$3^{\text {rd }}$ session: connecting ideas, feelings and behaviors.

$4^{\text {th }}$ session: (where is the evidence?) helping students search for evidence supporting and not supporting the distorted ideas.

$5^{\text {th }}$ session: introducing cognitive distortions and their impact on our mood and behaviors, as well as training on correcting distortions (All-or-nothing).

$6^{\text {th }}$ session: (over generalization) where participants were introduced to meaning and they were trained on correcting (over generalization) as a distorted idea.

$7^{\text {th }}$ session: mental filtering.

$8^{\text {th }}$ session: disqualifying positive events.

$9^{\text {th }}$ session: magnification and minimization. 
$10^{\text {th }}$ session: should or must statements.

$11^{\text {th }}$ session: labeling and personalization.

$12^{\text {th }}$ session: emotional reasoning and ending up the program with the post measurement.

In each session, they were introduced to cognitive distortion and given real life examples, as well as identifying and correcting it through evidence and logic. They were also given homework for identifying distorted ideas and working on correcting them.

\section{The Study Design}

The researcher used the survey methodology with the intention of identifying the level of depression and the sense of insecurity among the female Syrian refugees in the Zarqa public schools. Then, the experimental approach was used to examine the efficacy of correcting cognitive distortions in reducing their depression and feeling insecure.

The experimental group: pre-test / training program / post-test

$\mathrm{R} \quad \mathrm{O} 1 \times \mathrm{O} 2$

The control group: pre-test / no treatment / post-test

$\mathrm{O} 1 \mathrm{O} 2$

The Study Variables

Independent variable: the program of correcting cognitive distortions

Dependent variable: the degree of both scales (depression, sense of insecurity) among the female refugees.

\section{RESULTS}

This study aimed at identifying the level of depression and sense of insecurity among a sample of female refugee adolescents, and the impact of correcting cognitive distortions in reducing their depression and feeling insecure.

\section{Results Related to the $1^{\text {st }}$ Question}

What is the level of depression and feeling insecure among the female refugee adolescents in public schools?

To answer this question, means and standard deviations were calculated for the refugee adolescents' responses within the domain of depression. Table 1 reveals the results for this question.

Table 1. Results for question 1

\begin{tabular}{l|c|c|c|c|cc}
\hline \multicolumn{1}{c|}{ Domain } & No. items & $\begin{array}{c}\text { Entire degree } \\
\text { for domain }\end{array}$ & Mean & SD & \% & Degree \\
\hline Depression & 18 & 36 & 26.63 & 4.472 & 73.97 & Medium \\
\hline Feeling insecure & 27 & 54 & 37.51 & 6.644 & 69.46 & Medium \\
\hline Statistically significant at the level $(\alpha=0.05)$. &
\end{tabular}

It is clear in Table 1 that the degree of having depression and feeling insecure from the adolescents' point of view was medium, where the level of depression was $73.97 \%$, and the sense of insecurity was $69.46 \%$. 


\section{Results Related to the $2^{\text {nd }}$ Question}

Are there statistically significant differences at the level $(\boldsymbol{\alpha}=0.05)$ between the degrees average of experimental group and the degrees average of the control group regarding the level of depression and feeling insecure among the adolescents in the post-test, ascribed to the program of correcting cognitive distortions?

To answer this question, means and standard deviations were calculated for the performance of both groups within the pre and post-tests, as seen in Table 2 .

Table 2. Means \&SDs of the 2 groups' performance in the 2 tests

\begin{tabular}{|c|c|c|c|c|}
\hline Dimension & Test & Group & Mean & SD \\
\hline \multirow{4}{*}{ Depression } & \multirow{2}{*}{ Post } & Control & 31.50 & 2.799 \\
\hline & & Experimental & 24.40 & 3.239 \\
\hline & \multirow{2}{*}{ Pre } & Control & 33.30 & 1.829 \\
\hline & & Experimental & 29.70 & 4.170 \\
\hline \multirow{4}{*}{ Feeling insecure } & \multirow{2}{*}{ Post } & Control & 46.70 & 4.570 \\
\hline & & Experimental & 37.50 & 3.610 \\
\hline & \multirow{2}{*}{ Pre } & Control & 84.80 & 1.980 \\
\hline & & Experimental & 44.65 & 1.897 \\
\hline
\end{tabular}

It is clear in Table 2 the existence of obvious differences between the pre and post tests for both groups (control and experimental).

To see if these differences were statistically significant, ANCOVA was conducted to examine the performance of the sample participants of female refugee adolescents within the control and experimental groups, regarding the depression dimension, as seen in Table 3.

Table 3. Results of ANCOVA for performance regarding depression (post-test)

\begin{tabular}{l|c|c|c|c|c|c}
\hline \multicolumn{1}{c|}{ Source } & $\begin{array}{c}\text { Sum of } \\
\text { Squares }\end{array}$ & $\begin{array}{c}\text { Degrees of } \\
\text { Freedom }\end{array}$ & $\begin{array}{c}\text { Mean of } \\
\text { Squares }\end{array}$ & F value & $\begin{array}{c}\text { Statistical } \\
\text { significance }\end{array}$ & $\begin{array}{c}\text { Aita Square } \\
\text { (Impact) }\end{array}$ \\
\hline Pre-test & 0.535 & 1 & 0.0535 & 0.55 & 0.817 & 0.003 \\
\hline Group & 146.382 & 1 & 146.382 & 15.14 & 0.001 & 0.471 \\
\hline Error & 164.365 & 17 & 9.669 & & & \\
\hline Entire corrected & 416.95 & 19 & & & & \\
\hline
\end{tabular}

It is clear in Table 3 that there are statistically significant differences for the sample's performance on the scale of depression ascribed to the group's type. Aita Square (0.471) refers to the amount of impact for the independent variable (the indicative program) on the dependent variable (depression). To identify the sources of that difference, modified means and standard error were calculated for performance regarding the post-depression scale, according to the type of the group, as seen in Table 4.

Table 4. Modified Means \& Standard Errors for performance on the scale of depression (post-test)

\begin{tabular}{l|c|c}
\hline \multicolumn{1}{c|}{ Group } & Modified mean & Standard error \\
\hline Control & 31.653 & 1.179 \\
\hline Experimental & 24.247 & 1.179 \\
\hline
\end{tabular}

It is clear in Table 4 that there is an obvious difference between the averages of both performances for both groups, for the benefit of the experimental group.

Also, ANCOVA was calculated for performance on the scale of feeling insecure, according to the variable of group type, as seen in Table 5. 
Table 5. ANCOVA results for the dimension of feeling insecure (post-test)

\begin{tabular}{l|c|c|c|c|c|c}
\hline \multicolumn{1}{c|}{ Source } & $\begin{array}{c}\text { Sum of } \\
\text { Squares }\end{array}$ & $\begin{array}{c}\text { Degrees of } \\
\text { Freedom }\end{array}$ & $\begin{array}{c}\text { Mean of } \\
\text { Squares }\end{array}$ & F value & $\begin{array}{c}\text { Statistical } \\
\text { significance }\end{array}$ & $\begin{array}{c}\text { Aita Square } \\
\text { (Impact) }\end{array}$ \\
\hline Mutual variable & 0.890 & 1 & 0.895 & 0.005 & 0.826 & 0.003 \\
\hline Group & 175.599 & 1 & 175.599 & 9.794 & 0.006 & 0.366 \\
\hline Error & 304.805 & 17 & 17.930 & & & \\
\hline Entire corrected & 666.095 & 19 & & & & \\
\hline
\end{tabular}

It is clear in the table that there are statistically significant differences for the sample performance on the scale of feeling insecure, ascribed to the group's type, where F-value was (9.794), and Aita Square was (.0366). All of them are statistically significant values at the level $(\alpha=0.05)$, and that means the performance of the experimental group improved compared with the control group.

To identify the sources of these differences, modified means and standard error were calculated for the performance on the scale of feeling insecure according to the group's type, as seen in Table 6.

Table 6. Modified Means \& Standard Errors for performance on the scale of feeling insecure (post-test)

\begin{tabular}{l|c|c}
\hline \multicolumn{1}{c}{ Group } & Modified mean & Standard error \\
\hline Control & 46.944 & 1.179 \\
\hline Experimental & 37.959 & 1.179 \\
\hline
\end{tabular}

It is clear in table (6) that there is an obvious difference between the averages of both performances for both groups, for the benefit of the experimental group.

\section{DISCUSSION}

There is an impact for correcting cognitive distortions on reducing the level of depression and the sense of insecurity among the female refugee adolescents.

\section{Discussing Results Related to the $1^{\text {st }}$ Question}

What is the level of depression and feeling insecure among the female refugee adolescents in public schools?

The findings of this study indicated that the female refugee adolescents suffer from depression and sense of insecurity with a medium degree, and this result agrees with the results found by Saidoom \& Thabet (2012) who pointed out that refugees suffer from post-shock disorders, with a $54 \%$ degree.

It also agrees with the study of Al-Atrani (1995) which found out that $65 \%$ of individuals who experienced war and lost one of their relatives suffer from post-shock disorders.

The results agree also with the results of a study conducted by the Algerian Ministry of Health with cooperation with UNICEF in 2002 with the aim of identifying the spreading scope of post-shock disorders among adolescent children who were exposed to terrorism. This study found that the children and teenagers in most states were suffering from post-shock disorders, with medium percentages.

That could be explained by the fact that several individuals who experience war are usually exposed to several scenes of violence and abuse such as robbery and theft which occur during the periods of insecurity and instability in the country, in addition to seeing events of damage and massive killings which cause severe psychological and physical signs, severe panic and fear, sense of being insecure, and severe worry related to future and destiny.

\section{Discussing Results Related to the $2^{\text {nd }}$ Question:}

Are there statistically significant differences at the level $(\alpha=0.05)$ between the degrees average of experimental group and the degrees average of the control group regarding the level of depression and feeling insecure among the adolescents in the post-test, ascribed to the program of correcting cognitive distortions? 
Results found out in this study indicated that there are statistically significant differences between the experimental and control groups in reducing the level of depression and sense of insecurity for the benefit of the experimental group. This result agrees with the results of Al-Sabnani study (2005), Badran's study (2010), Kubani, et.al (2003), and the study of Geradi, et.al (2012) which all used the behavioral-cognitive treatment for dealing with post-shock disorders, where their results referred to the efficacy of these programs in reducing troubles and disorders resulted from shocks.

Several psychological troubles and behavioral disorders, in addition to negative feelings such as worry and depression are resulting from the way these individuals explain their surrounding accidents and events (Corey, 2011). Individuals may be exposed to the same shocking incidents, but their behavioral responses and emotional reactions may differ according to the way they perceived these incidents. So, working on the course of ideas and correcting though errors contribute largely to modifying the individuals' negative feelings and behaviors.

\section{RECOMMENDATIONS}

The researcher recommends conducting more studies on displaced people or migrants, as well as focusing on remedial programs for their need to several programs that would help them cope with the asylum conditions.

\section{REFERENCES}

Abu Ulayyan, Hanan (2008). The Level of Anxiety, Perceived Self-sufficiency and Academic Achievement among divorced teenagers and their peers in the Arab families in Jordan. Unpublished PhD dissertation, Amman Arab University, Amman

Al-Atrani, Sa'eid (1995). Consequences of being exposed to psychological troubles among the preparatory stage students of the families who were the victims of Ameriyah disaster. Unpublished M.A dissertation, Al-Mustansiriya University, Iraq.

Al-Nayyal, Maysa (2008). A Recent Study of Adolescence. $2^{\text {nd }}$ part, University Knowledge Company.

Al-Rimawi, Mohammad (2003). Growth psychology (Childhood \& Adolescence). $1^{\text {st }}$ ed., Dar Al-Maseira, Amman, Jordan.

Al-Sabnani, Eman (2005). The Efficacy of a behavioral-cognitive program in reducing post-shock disorder among abused kids. Unpublished M.A dissertation, University of Jordan, Amman.

Badbesky\&Gronberg (2001). Mind above Emotion. Translated by Ma'moon Al-Mubayed, $1^{\text {st }}$ ed., Islamic Office, Amman.

Badran, Su'ad (2010). The Impact of a Remedial Cognitive-Behavioral Program in Reducing the Symptoms of Post-shock Disorders among a Sample of Abused Women in Amman. Unpublished M.A dissertation, Jordan University, Amman.

Blanch, Jan (1985). The Dictionary of Psychological Analysis Terms, translated by Mustafa Hijazi, Beirut, the University Corporation for studies and publishing.

Brisk man, Linda and Goddard Chris. (2014). Australia Traffics and abuses Asylum seeker children. The comment age, $4,376$.

Burnett, A. and Peel, M. (2001). Health needs of asylum seekers and refugees. British medical journal, 3.22-544-547.

Data, unhcr.org/Syrian refugees/regional.php.

Foster. B.A. (2010). A statistical overview f displaced persons. National social science, 17(1), 38-44.

Geradi, M. Rothbaum, O.B Ressler, K. and Heekin M. (2008) virtual reality exposure therapy using a virtual Iraq: case report. Journal of traumatic stress. 21 (2), 209-213.

Gerow, R Josh. (1993). Psychology: An introduction $3^{\text {rd }}$. Havper Collins publisher. USA.

Lipson, G. (1993). Afghan refugees in California: mental health issues 14(4), 411-423.

Marina, A. Jelukouic, (1998). Impact disablement on the psychological well - being of refugee children. International Review of psychiatry 10.186-195.

Mhaidat, Fatin (2011). The Adaptation Problems Among Female Adolescents in Divorced Families, and the Impact of Correcting Cognitive Distortions in Reducing these Problems. Unpublished PhD dissertation, Jordan University, Amman.

Radwan, Samer (2006). The Psychological Effects of Shocking Experiences, Extremist Exhaustions, and Mental Slaughtering. Journal of Arabian Psychological Sciences, 3 (12) 64-94.

Rice, F. (1992). Human Development. Second New Jersey, preoptic hall.

United Nations High Commission for Refugees 2014.

Zahran, Hamed (1985). Growth psychology (Childhood \& Adolescence). Books World, Beirut. 